\title{
(2) OPEN ACCESS \\ Evaluating the safety of mental health-related prescribing in UK primary care: a cross-sectional study using the Clinical Practice Research Datalink (CPRD)
}

- Additional supplemental material is published online only. To view, please visit the journal online (http://dx.doi. org/10.1136/bmjqs-2021013427).

For numbered affiliations see end of article.

\section{Correspondence to} Mr Wael Y Khawagi, Centre for Pharmacoepidemiology and Drug Safety, University of Manchester Faculty of Biology, Medicine and Health, Manchester M13 9PT, UK; w.khawagi@tu.edu.sa

Received 25 March 2021 Accepted 7 August 2021
D) Check for updates

(c) Author(s) (or their employer(s)) 2021. Re-use permitted under CC BY-NC. No commercial re-use. See rights and permissions. Published by BMJ.

To cite: Khawagi WY, Steinke D, Carr MJ, et al. BMJ Qual Saf Epub ahead of print: [please include Day Month Year]. doi:10.1136/ bmjqs-2021-013427

\author{
Wael Y Khawagi (D) ,,2 Douglas Steinke, ${ }^{1,3}$ Matthew J Carr, ${ }^{1,4}$ \\ Alison K Wright (D) , ${ }^{1,3}$ Darren M Ashcroft, ${ }^{1,4}$ Anthony Avery, ${ }^{4,5}$ \\ Richard Neil Keers (D) 1,6
}

\begin{abstract}
Background Most patients with mental illness are managed in primary care, yet there is a lack of data exploring potential prescribing safety issues in this setting for this population.

Objectives Examine the prevalence of, betweenpractice variation in, and patient and practice-level risk factors for, 18 mental health-related potentially hazardous prescribing indicators and four inadequate medication monitoring indicators in UK primary care. Method Cross-sectional analyses of routinely collected electronic health records from 361 practices contributing to Clinical Practice Research Datalink GOLD database. The proportion of patients 'at risk' (based on an existing diagnosis, medication, age and/or sex) triggering each indicator and composite indicator was calculated. To examine between-practice variation, intraclass correlation coefficient (ICC) and median OR (MOR) were estimated using two-level logistic regression models. The relationship between patient and practice characteristics and risk of triggering composites including 16 of the 18 prescribing indicators and four monitoring indicators were assessed using multilevel logistic regression.
\end{abstract} Results $9.4 \%$ of patients 'at risk' (151 469 of 1 611 129) triggered at least one potentially hazardous prescribing indicator; between practices this ranged from $3.2 \%$ to $24.1 \%$ (ICC 0.03 , MOR 1.22). For inadequate monitoring, $90.2 \%$ of patients 'at risk' (38 671 of 42879 ) triggered at least one indicator; between practices this ranged from $33.3 \%$ to $100 \%$ (ICC 0.26, MOR 2.86). Patients aged 35-44, females and those receiving more than 10 repeat prescriptions were at greatest risk of triggering a prescribing indicator. Patients aged less than 25, females and those with one or no repeat prescription were at greatest risk of triggering a monitoring indicator.

Conclusion Potentially hazardous prescribing and inadequate medication monitoring commonly affect patients with mental illness in primary care, with marked between-practice variation for some indicators. These findings support health providers to identify improvement targets and inform development of improvement efforts to reduce medication-related harm.

\section{INTRODUCTION}

Medications are the most commonly used treatment for mental illness, ${ }^{1}$ and there has been substantial growth in the proportion of individuals worldwide using medications for mental illness. ${ }^{2-5}$ Prescribing medications for patients with mental illness may be complicated by high-dose antipsychotics and combination regimens, the use of psychotropics with high risk of harm, high prevalence of patient comorbidities and polypharmacy creating drugdisease and drug-drug interactions which may increase the risk of harmful adverse events. ${ }^{6}$ A recent systematic review and meta-analysis reported that the highest prevalence of preventable harm due to medication was at the prescribing and monitoring stages of the medication use process, and psychotropic medication was among the most common therapeutic groups associated with preventable medication harm. ${ }^{7}$

However, most medication safety research for patients with mental illness has focused on hospital settings, with little data available on prescribing safety in primary care for this population. ${ }^{8} 9$ This is important as primary care is often the first point of contact for people with mental illness with $\sim 90 \%$ of adults managed entirely in primary care, including those with high levels of need and complexity. ${ }^{10-12}$ There is evidence that patients with mental illness may experience poor quality care affecting both their physical and mental healthcare needs in primary care. ${ }^{10} 12$ Also, research has shown that less than half of general 
practitioner (GP) trainees in England and Wales undertook a training placement in a mental health setting between 2013 and 2015. ${ }^{13}$ Accordingly, GPs may not always feel capable of managing patients with mental illness and making alterations to an established treatment. ${ }^{10}$ In addition, the increasing demand for primary care services globally, which is expected to grow, may further impact adversely on the quality of care provided for patients with mental illness. ${ }^{12}$ 14-17

Prescribing safety indicators (PSIs) provide a means of assessing prescribing safety, identifying patients at high risk of medicine-related harm, enabling interventions and helping to avoid patient harm and its consequences such as hospitalisation. ${ }^{18} 19$ Use of PSIs has been growing in keeping with the WHO's Third Global Patient Safety Challenge in 2017 'Medication Without Harm', which recognises the importance of hazardous prescribing. ${ }^{20}{ }^{21}$ Suites of PSIs are already forming part of several successful multifaceted interventions in the UK and the USA, allowing for realtime feedback on prescribing safety in primary care to reduce the risk of preventable drug-related harm. ${ }^{21-29}$ Across England, PSIs have been rolled out to electronically search clinical records and identify individual patients at risk of hazardous prescribing in primary care. ${ }^{30}$ They are also being used for benchmarking at practice level as with the National Therapeutic Indicators in Scotland, the National Prescribing Indicators in Wales and the Quality and Outcomes Framework (QOF) in England. ${ }^{31-33}$ However, in all these initiatives, a limited number of mental health-related PSIs were included. To address this need, the first mental health-related suite of PSIs has been recently developed using the Delphi method following a systematic review to identify a comprehensive list of potential PSIs from published literature. ${ }^{3435}$ This suite covers a broad range of contemporary safety concerns under a range of different mental health problems and related medication classes, but has yet to be implemented in primary care health records, and the prevalence of potentially hazardous prescribing in those with mental illness therefore remains unknown. Therefore, the aim of this research study was to evaluate prescribing safety for patients with mental illness in UK primary care using a tailored PSI suite by examining their prevalence, variation between general practices, and patient and practice-level risk factors, while also determining their practice-level reliability.

\section{METHODS}

\section{Study design, data source and population}

A cross-sectional study was carried out using data retrieved from the Clinical Practice Research Datalink (CPRD GOLD), a primary care database of anonymised electronic health records from contributing general practices in the UK. ${ }^{36}$ It includes approximately $6.9 \%$ of the UK population, and is considered broadly representative of the general population in terms of age, sex and ethnicity. ${ }^{36}$

The study population consisted of all patients registered with general practices in the UK contributing to the CPRD GOLD, who had uploaded data after the audit date (30 September 2019) and were deemed to be of research quality 12 months before the audit date (ie, before 1 October 2018). Research quality was determined using the two sets of data quality criteria provided by the CPRD: acceptability for patients (ie, registration status, recording of events and valid age and gender) and up to standard time for practices (ie, continuity of recording). ${ }^{36}$ Within the study population, data were extracted for all patients with the potential to trigger each PSI based on an existing diagnosis, medication, their age and/or sex. Diagnoses and prescriptions of medications are recorded in the CPRD using Read codes and product codes, respectively. The codes to define each PSI were reviewed by two pharmacists of the research team (RNK and DS). A full list of the codes is available at the ClinicalCodes repository (https://clinicalcodes.rss.mhs.man.ac.uk). ${ }^{37}$ A drug preparation algorithm published previously was used to prepare drug exposure data. ${ }^{38} 39$

\section{Outcomes}

We operationalised a subset of 22 PSIs (18 potentially hazardous prescribing indicators and four inadequate medication monitoring indicators) from a recently developed mental health-related PSI suite that are relevant to primary care and feasible for application in the CPRD GOLD data. ${ }^{35}$ Relevance and feasibility were established by the research team which included a specialist mental health pharmacist (RNK) and a pharmacoepidemiologist (DS) with experience in using CPRD data. Indicators were not included if the data were not captured in the CPRD such as over-thecounter therapy, or if the indicator contained a medication usually prescribed by mental health trusts that might not be recorded in GP records such as clozapine and long-acting antipsychotic injections. ${ }^{36}{ }^{40}$ Online supplemental file 1 lists the 22 included PSIs with their operational definitions.

To examine their prevalence, each PSI comprised a denominator and a numerator. The denominator included all patients with the potential to trigger an indicator based on an existing diagnosis, medication, their age and/or sex. For example, with indicator P10, patients would be included in the denominator if they had a record of dementia diagnosis, and for indicator P11, patients would be included if they were aged 65 or older, more than 6 months before the audit date. The numerator included patients who triggered the indicator by receiving the potentially hazardous prescription, having no record of the required monitoring or having no record of the recommended prescription.

Additionally, three composite indicators were defined to summarise the overall prevalence and to 
assess the risk factors. ${ }^{41-44}$ For each composite indicator, patients were eligible to be included if they were 'at risk' for any one of the relevant individual indicators, and if a patient was eligible for more than one indicator they were counted once. Therefore, the composite indicators describe the number of patients triggering at least one of the relevant indicators divided by the number of patients with the potential to trigger any of the relevant indicators. The first composite consisted of all potentially hazardous prescribing indicators (P1-P18), the second consisted of all inadequate medication monitoring indicators (M1-M4) and the third consisted of all potentially hazardous prescribing indicators except P11 (specifically for the elderly) and P13 (specifically for female patients). The reason for excluding these two indicators was to allow relevant comparisons between genders and age groups in terms of the overall risk.

\section{Statistical analysis}

The proportion of patients triggering each PSI and composite indicator was calculated with $95 \%$ CIs. To examine the variability in the prevalence of PSIs between practices, the intraclass correlation coefficient (ICC) was estimated using an empty two-level logistic regression model and a two-level logistic regression model adjusted with patient variables, age $(5$-knot restricted cubic spline), sex and number of repeat medications. The ICC estimates the proportion of the total variation in an indicator that is attributable to the variation between practices. ${ }^{42}$ In addition, we calculated the median OR (MOR) for each indicator using the same case-mix model. The MOR is the median of all possible ORs of triggering an indicator in two patients with identical characteristics, but registered with two different practices. It can also be conceptualised as the increased risk that an individual would encounter when moving from one practice to another. The MOR is always equal to or higher than 1 . Higher MOR values indicate more variation between practices. The advantage of the MOR is that it is directly comparable with the ORs for patient and practicelevel variables. ${ }^{45} 46$

Furthermore, the reliability for each PSI and each composite indicator was estimated using the Spearman-Brown prophecy formula defined as $(n-I C C) /(1+(n-1) * I C C)$, where $n$ represents the number of patients in the denominator per practice. ${ }^{42}$ The reliability coefficient indicates if the observed practice-level variation is due to true practice differences or due to chance. ${ }^{47}$ For example, an indicator with a low ICC value would require higher numbers of 'patients at risk' for a reliable comparison. ${ }^{42}$ The reliability ranges between 0 and 1 , where a higher value indicates a higher level of reliability. Values greater than 0.7 are usually deemed to suggest adequate reliability for benchmarking. ${ }^{41}$ The reliability for a theoretical practice (using the median number of patients in the denominator) was calculated to provide an overall estimate of reliability. The proportion of practices with a reliability measure greater than 0.7 was measured. To visualise the variation between practices, funnel plots of the observed proportions and caterpillar plots of the shrunken practice-level residuals (with 95\% CIs) from the case-mix model were generated for each PSI and each composite indicator with an overall reliability greater than 0.7 (online supplemental file 2).

The associations between potentially hazardous prescribing (composite 3 ) and inadequate medication monitoring (composite 2) with both practice-level and patient-level variables were examined using two-level logistic regressions. Initially, unadjusted ORs with 95\% CIs were calculated and then subsequently adjusted for patient and practice variables. Patient-level variables considered were age group $(<25,25-34,35-44$, $45-54,55-64,65-74$ and $>74)$, sex and number of repeat medications $(0-1,2-4,5-7,8-10$ and $>10)$, which is defined as $\geq 3$ prescriptions of the same medicine within the 12 months leading up to 30 September $2019 .{ }^{48}$ Practice-level variables were number of patients per general practice $(<6000,6001-9000$, 9001-12 000 and >12 000), practice-level index of multiple deprivation (IMD) quintile and location of practice by country of the UK. The covariates were selected based on prior literature. ${ }^{41}{ }^{42}$ Composite 1 was not included in this analysis as P11 was not relevant to all age groups and P13 was not relevant to both genders. Statistical analyses were performed using Stata V.16 (StataCorp, College Station, Texas). Funnel plots were created using a tool by Public Health England. ${ }^{49}$

\section{RESULTS}

A total of 361 general practices were eligible for inclusion with 3001877 registered patients. Most included practices were from Scotland $(n=159,43 \%)$, followed by England ( $\mathrm{n}=99,26.8 \%)$, Wales $(\mathrm{n}=98,26.5 \%)$ and Northern Ireland ( $\mathrm{n}=14,3.8 \%)$. In total, 1613207 (53.8\%) patients were at risk of triggering any one of the 22 PSIs due to their age, sex, disease and/or prescription. Table 1 shows the observed prevalence, ICCs, MOR and reliability of each PSI and composite indicator. The online supplemental file 2 shows the variation between practices for each indicator and each composite indicator with adequate reliability before and after adjusting for patient characteristics.

\section{Prevalence of composite indicators}

For the composite that contained only prescribingrelated indicators (composite 1, P1-P18), 151469 of 1611129 (9.4\%, 95\% CI 9.4\% to 9.5\%) at-risk patients were affected by at least one potentially hazardous prescription. For the composite that included only monitoring indicators (composite 2, M1-M4), 38671 of 42879 (90.2\%, 95\% CI 89.9\% to $90.5 \%$ ) at-risk patients were affected by at least one 


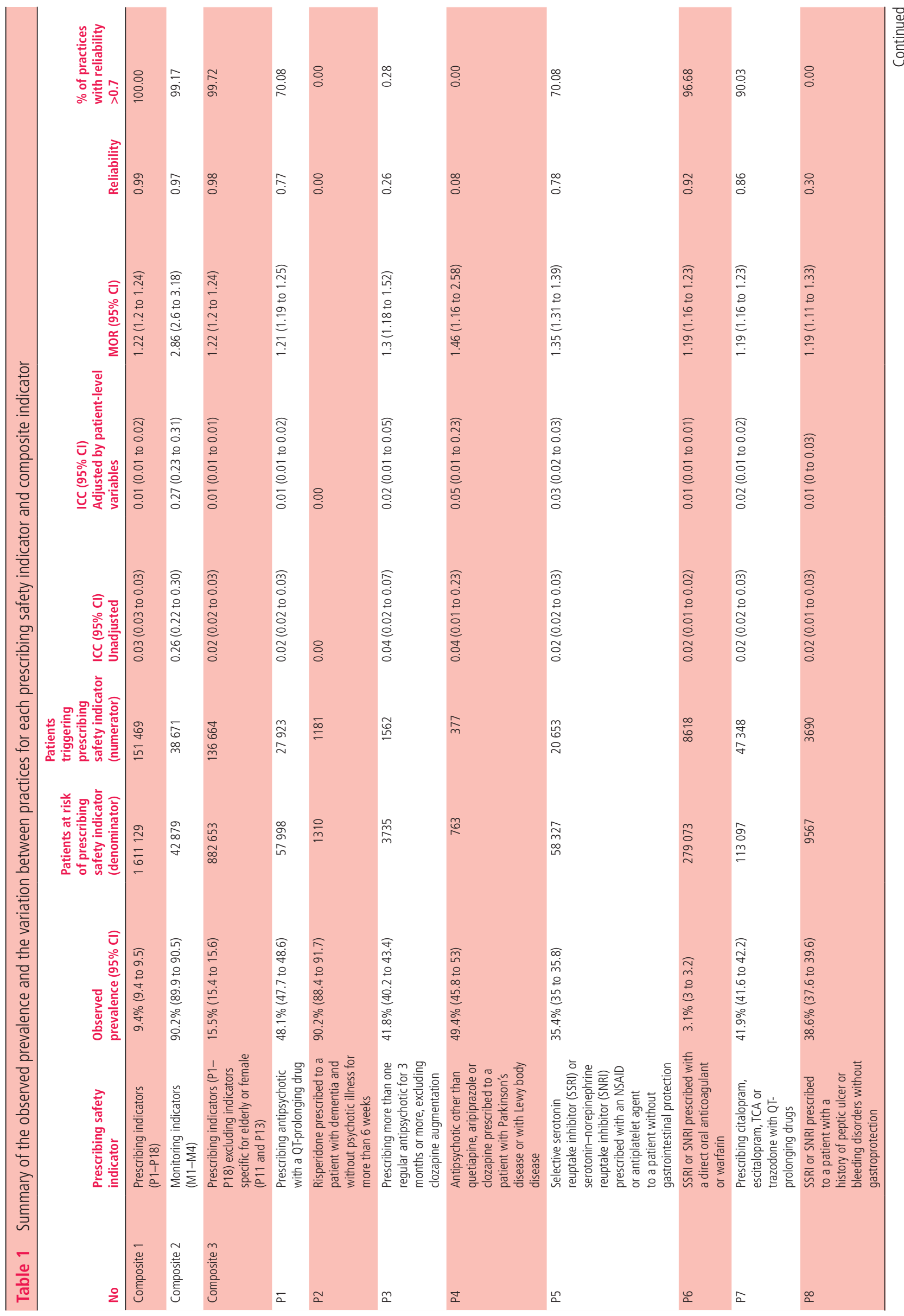

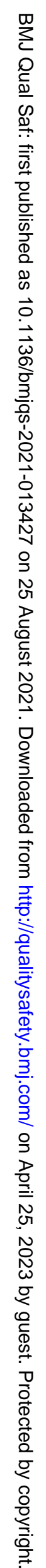




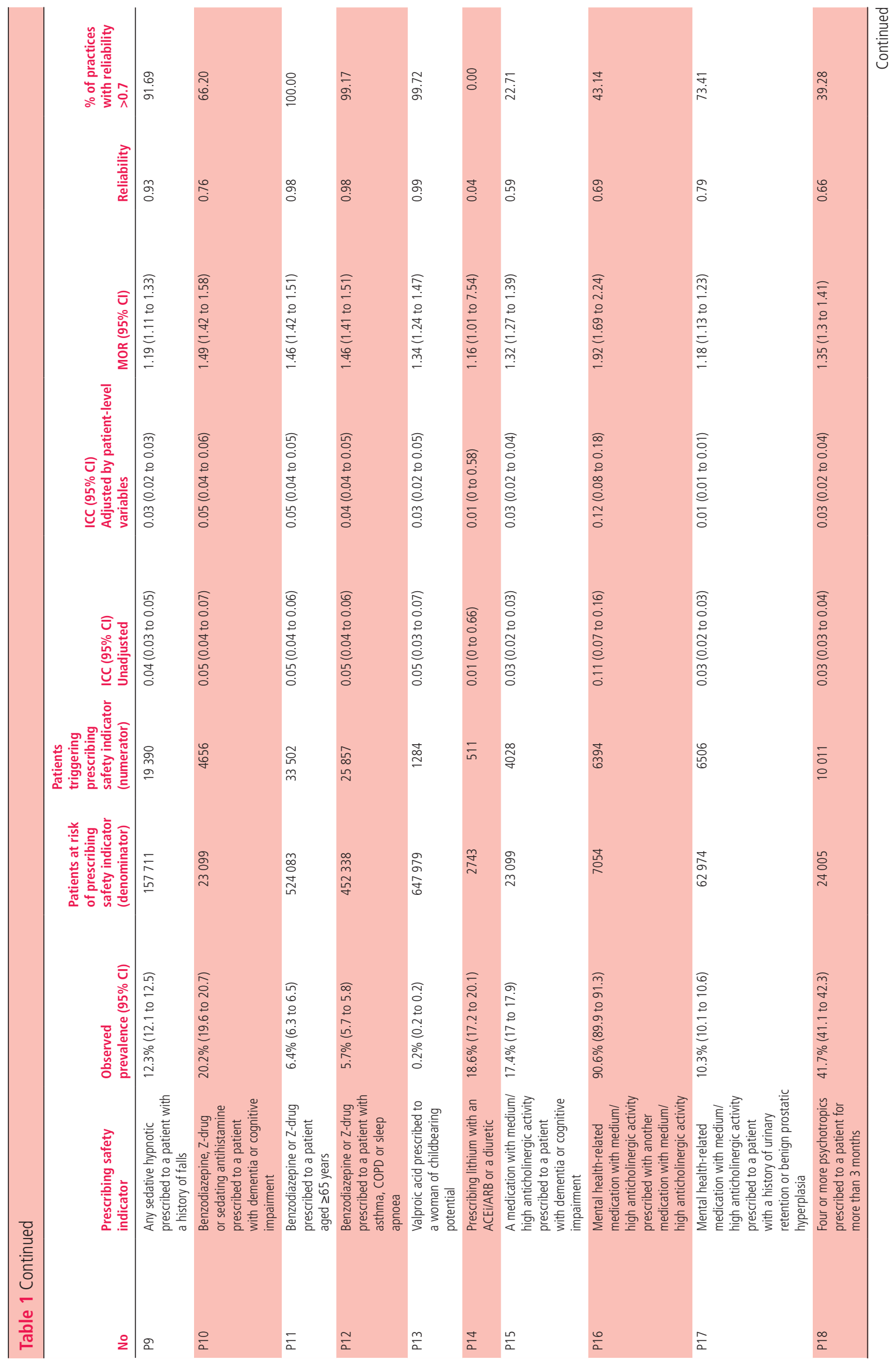




\section{Original research}

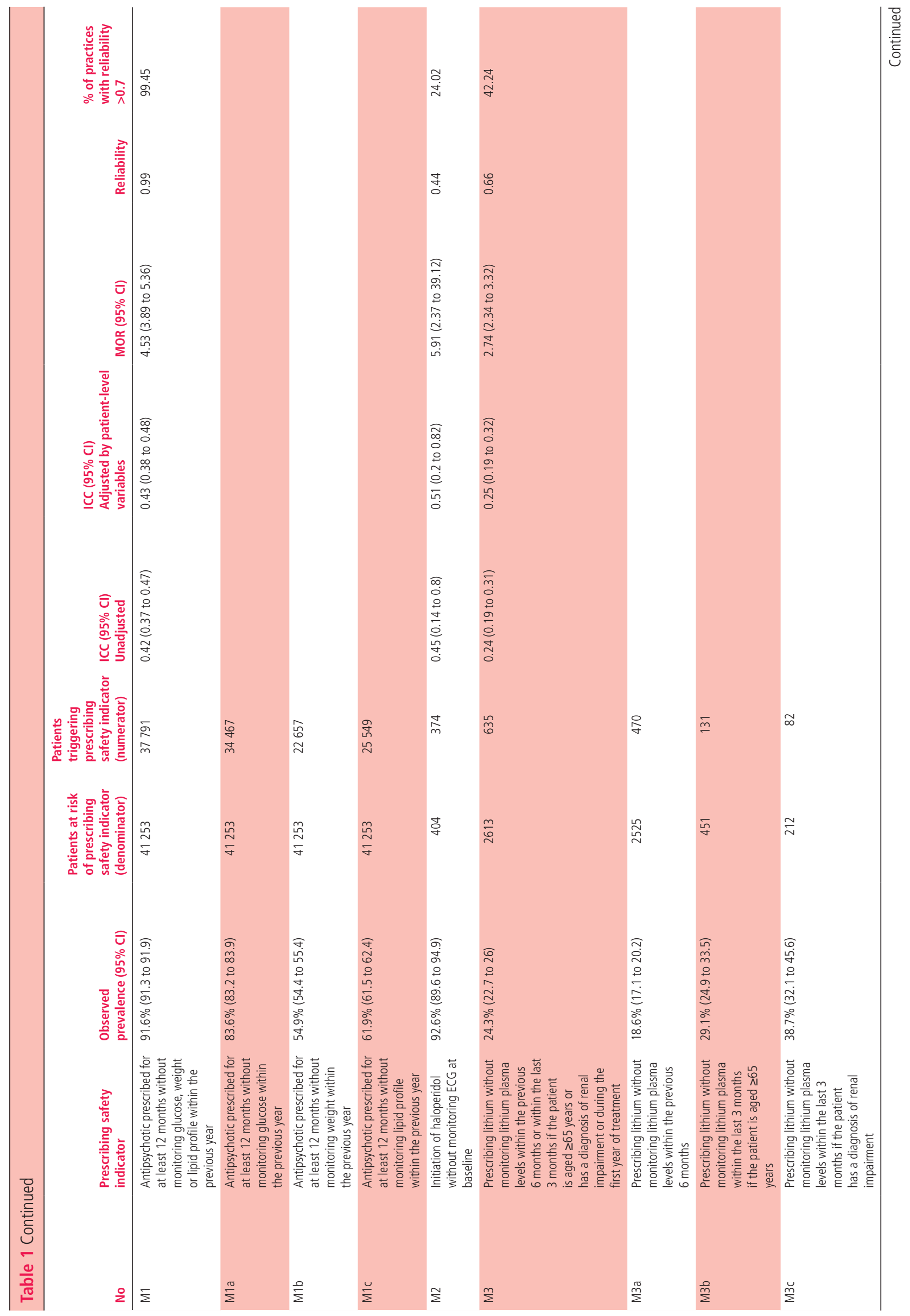

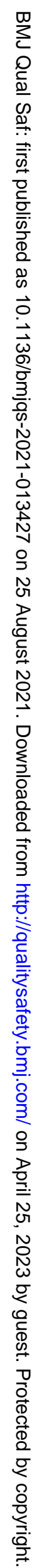




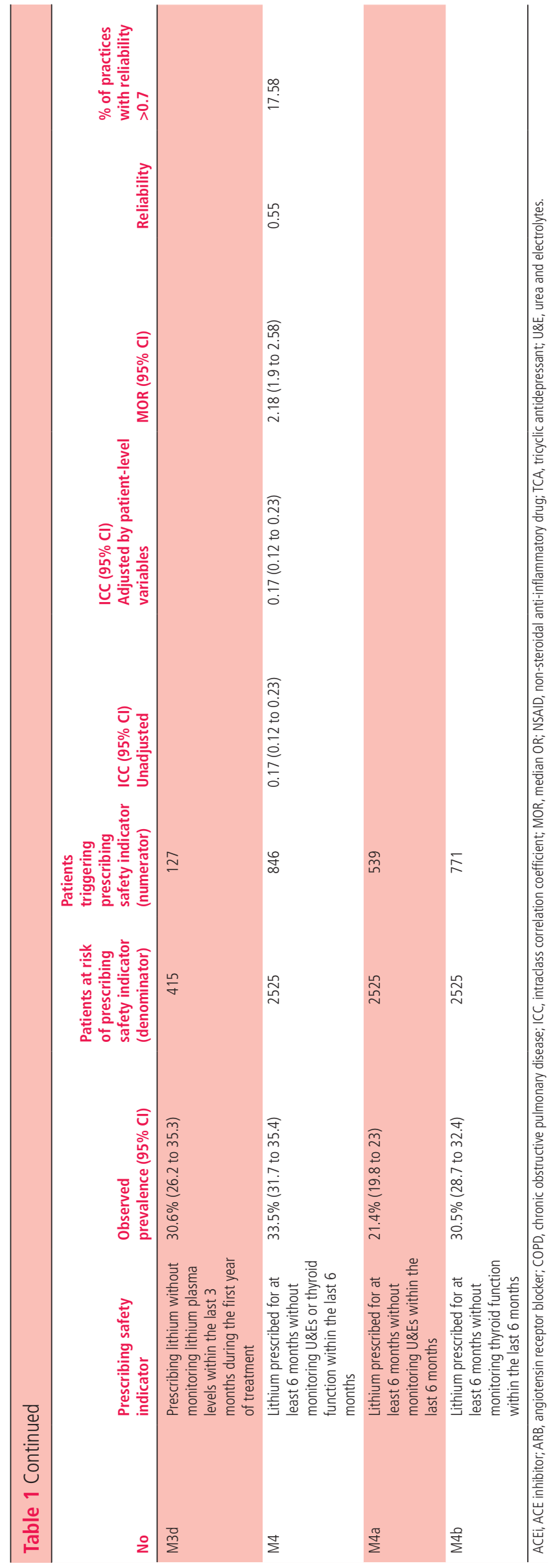

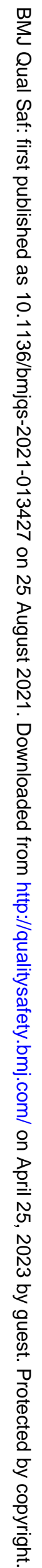


potentially hazardous medication-monitoring episode. For composite 3 (P1-P18 excluding P11 and P13), 136 664 of 882653 (15.5\%, 95\% CI 15.4\% to $15.6 \%)$ patients received at least one potentially hazardous prescription.

\section{Prevalence of individual PSIs}

The proportion of patients triggering each indicator varied considerably across the 22 PSIs from $0.2 \%$ to $92.6 \%$. For the potentially hazardous prescribing indicators, the prevalence ranged from $0.2 \%$ to $90.6 \%$. For the inadequate monitoring indicators, the prevalence ranged from $24.3 \%$ to $92.6 \%$. Of those that triggered at least one indicator, the majority triggered just one indicator $(n=110144,65.7 \%), 20.9 \%(n=35$ 093) triggered two indicators, $8 \%(n=13439)$ triggered three indicators and 5.4\% $(\mathrm{n}=9108)$ triggered at least four indicators.

\section{Variation between practices}

Variation between practices in terms of the observed prevalence of potentially hazardous prescribing measured by prescribing composite (P1-P18, composite 1) ranged from $3.2 \%$ to $24.1 \%$ (median $9.3 \%$, IQR 7.6\%-11.2\%). However, when measured using the ICC, $3 \%$ of this variation was attributable to differences between practices, and only $1 \%$ persisted after adjusting for patient characteristics. The MOR value was 1.22 (95\% CI 1.20 to 1.24). For the monitoring composite (M1-M4, composite 2), the observed prevalence ranged from $33.33 \%$ to $100 \%$ (median $91.8 \%$, IQR $84.54 \%-96.9 \%$ ), with $27 \%$ of variation being due to differences between practices after adjusting for patient characteristics and MOR 2.86 (95\% CI 2.60 to 3.18 ). Figure 1 shows the proportion of patients receiving potentially hazardous prescribing and inadequate medication monitoring for each general practice.

Of the 22 PSIs, eight prescribing indicators and three monitoring indicators had reliability scores lower than the recommended level of 0.7 for a practice that was of median size of all practices implying inadequate reliability. The proportion of practices with adequate reliability for the remaining indicators ranged from $66.2 \%$ to $100 \%$. However, all composite indicators had reliability scores above 0.9 , with over $99 \%$ of practices having reliability $>0.7$.

When investigating the variation of individual PSIs, after controlling for patient characteristics, the highest variation for a prescribing PSI was for P16 (related to prescribing two medications with anticholinergic activity) with $\mathrm{ICC}=0.12$ and $\mathrm{MOR}=1.92(95 \% \mathrm{CI}$ 1.69 to 2.24). However, the highest variation for prescribing PSIs with adequate reliability $(>0.7)$ was for P10 and P11 (both related to benzodiazepine or Z-drug prescribing) with ICC $=0.5$ for both PSIs and $\mathrm{MOR}=1.49(95 \%$ CI 1.42 to 1.58$)$ and $1.46(95 \%$ CI 1.42 to 1.51), respectively. However, for individual monitoring PSIs with adequate reliability, the highest variation was for M1 (related to monitoring the physical health of patients receiving an antipsychotic) with $\mathrm{ICC}=0.43$ and $\mathrm{MOR}=4.53$ (95\% CI 3.89 to 5.36).

\section{Patient and practice characteristics associated with potentially hazardous prescribing indicators (composite 3)}

Table 2 shows the prevalence of patients triggering potentially hazardous prescribing indicators (composite 3, P1-P18 excluding P11 and P13) by patient and practice-level characteristics, and the unadjusted and adjusted ORs (with 95\% CIs) derived from the two-level logistic regression model. All the patient-level characteristics included in the analysis were significantly associated with the risk of receiving potentially hazardous prescribing in the univariable and multivariable models.

In the univariable model, the risk of receiving potentially hazardous prescribing was increasing with age and the number of repeat prescriptions. After adjustment, the number of repeat prescriptions continued
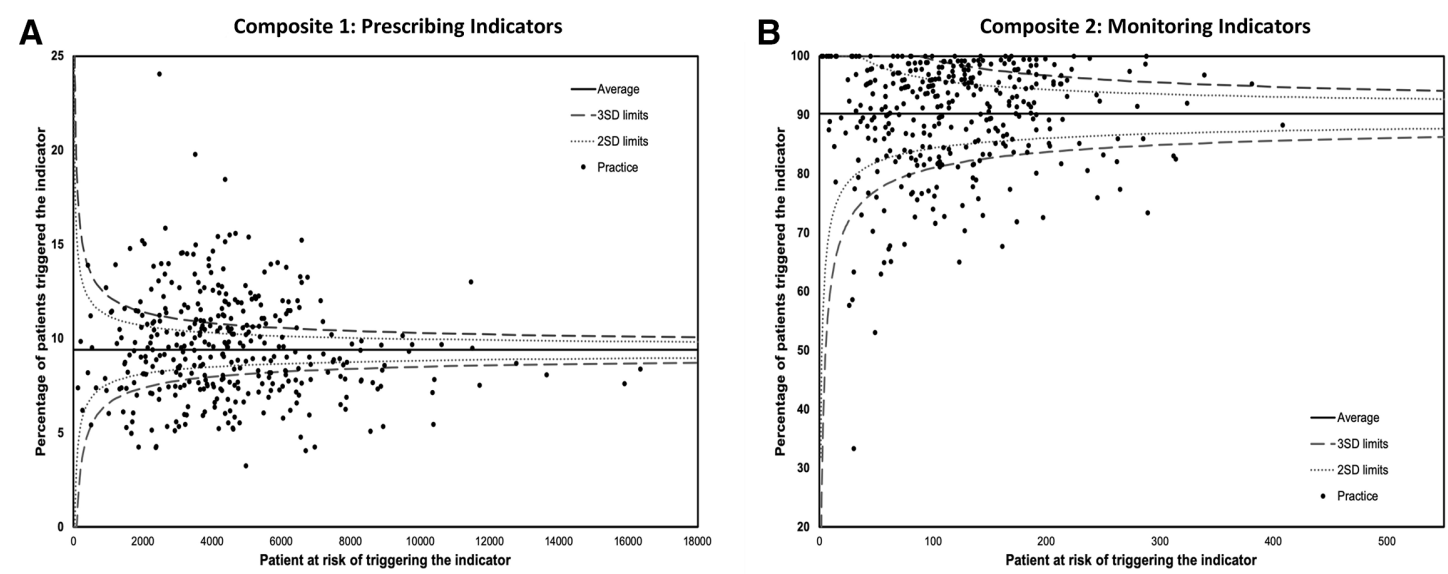

Figure 1 Proportion of (A) patients receiving at least one potentially hazardous prescribing (composite 1 ) and (B) patients experiencing at least one inadequate medication monitoring (composite 2) for each general practice. 
Table 2 Prevalence of patients receiving at least one potentially hazardous prescribing (composite 3) by patient and practice-level characteristics and multilevel logistic regression unadjusted and adjusted ORs (95\% Cls)

\begin{tabular}{|c|c|c|c|}
\hline \multirow[b]{2}{*}{ Variable ( $\mathrm{n}$ at risk) } & \multirow[b]{2}{*}{$\%$ prevalence $(95 \% \mathrm{CI})$} & \multicolumn{2}{|l|}{ OR $(95 \% \mathrm{CI})$} \\
\hline & & Unadjusted & Adjusted \\
\hline \multicolumn{4}{|l|}{ Age } \\
\hline$<25(128$ 141) & $4(3.9$ to 4.1$)$ & 1 & 1 \\
\hline $25-34(118374)$ & $9.9(9.8$ to 10.1$)$ & 2.62 (2.53 to 2.71$)$ & $2.22(2.14$ to 2.30$)$ \\
\hline 35-44 (115 374) & $13.9(13.7$ to 14.1$)$ & 3.89 (3.77 to 4.02$)$ & 2.34 (2.26 to 2.42$)$ \\
\hline $45-54(135518)$ & $17.7(17.5$ to 17.9$)$ & $5.22(5.06$ to 5.38$)$ & 2.03 (1.96 to 2.09$)$ \\
\hline 55-64 (134 562) & 19.7 (19.5 to 19.9$)$ & 5.89 (5.71 to 6.07$)$ & $1.60(1.55$ to 1.65$)$ \\
\hline $65-74(120$ 225) & 19.5 (19.3 to 19.7$)$ & $5.92(5.74$ to 6.11$)$ & $1.16(1.12$ to 1.20$)$ \\
\hline$>74(130459)$ & $22.9(22.6$ to 23.1$)$ & 7.41 (7.18 to 7.64$)$ & 1.11 (1.08 to 1.15$)$ \\
\hline \multicolumn{4}{|l|}{ Sex } \\
\hline Male (400 029) & $12.2(12.1$ to 12.3$)$ & 1 & 1 \\
\hline Female (482 624) & $18.2(18.1$ to 18.3$)$ & $1.6(1.58$ to 1.62$)$ & $1.43(1.41$ to 1.45$)$ \\
\hline \multicolumn{4}{|c|}{ Number of drugs on repeat prescription } \\
\hline 0 or $1(361502)$ & 3.7 (3.6 to 3.7) & 1 & 1 \\
\hline $2-4(232723)$ & $13.2(13$ to 13.3$)$ & 3.94 (3.86 to 4.03$)$ & 3.99 (3.91 to 4.08$)$ \\
\hline 5-7 (133 179) & 23.4 (23.2 to 23.6$)$ & $7.98(7.81$ to 8.15$)$ & 9.16 (8.95 to 9.38$)$ \\
\hline 8-10 (80 072) & 32.5 (32.2 to 32.8$)$ & $12.55(12.26$ to 12.84$)$ & $15.52(15.12$ to 15.93$)$ \\
\hline$>10(75$ 177) & 47.4 (47.1 to 47.8$)$ & $23.54(23.01$ to 24.08$)$ & $30.22(29.44$ to 31.02$)$ \\
\hline \multicolumn{4}{|l|}{ List size } \\
\hline$<6000(130159)$ & $16.2(16$ to 16.4$)$ & 1 & 1 \\
\hline $6001-9000$ (270 949) & $16.4(16.2$ to 16.5$)$ & 1.04 (0.97 to 1.12$)$ & $1.03(0.98$ to 1.08$)$ \\
\hline $9001-12000(210388)$ & $15.6(15.5$ to 15.8$)$ & $0.99(0.91$ to 1.08$)$ & $1.02(0.96$ to 1.08$)$ \\
\hline$>12000(271157)$ & $14.1(14$ to 14.3$)$ & $0.88(0.81$ to 0.96$)$ & 1.01 (0.95 to 1.07$)$ \\
\hline \multicolumn{4}{|c|}{ Practice-level index of multiple deprivation quintile } \\
\hline 1 least deprived (151 968) & $13.2(13.1$ to 13.4$)$ & 1 & 1 \\
\hline $2(140183)$ & $15.3(15.1$ to 15.5$)$ & $1.19(1.08$ to 1.31$)$ & 1.08 (1.01 to 1.15$)$ \\
\hline $3(169054)$ & 15 (14.8 to 15.2$)$ & $1.18(1.07$ to 1.29$)$ & 1.03 (0.96 to 1.09$)$ \\
\hline $4(195532)$ & $16.3(16.1$ to 16.4$)$ & 1.31 (1.19 to 1.43$)$ & $1.08(1.01$ to 1.15$)$ \\
\hline 5 most deprived (225 916) & $16.8(16.7$ to 17$)$ & 1.37 (1.25 to 1.51$)$ & 1.10 (1.03 to 1.17$)$ \\
\hline \multicolumn{4}{|l|}{ Country } \\
\hline England (247 545) & $13(12.8$ to 13.1$)$ & 1 & 1 \\
\hline Northern Ireland (35 773) & 22 (21.6 to 22.5 ) & 1.91 (1.67 to 2.18 ) & 1.47 (1.33 to 1.63$)$ \\
\hline Scotland (328 773) & $16.9(16.8$ to 17.1$)$ & 1.34 (1.26 to 1.43$)$ & $1.17(1.11$ to 1.23$)$ \\
\hline Wales (270 562) & $15.1(15$ to 15.3$)$ & $1.19(1.11$ to 1.28$)$ & $0.95(0.91$ to 1.00$)$ \\
\hline
\end{tabular}

to have the same relationship; the prevalence of hazardous prescribing in patients receiving $0-1$ repeat prescription was $3.7 \%$ compared with $47.4 \%$ in those with $>10$ repeat prescriptions (adjusted OR 30.22, $95 \%$ CI 29.44 to 31.02$)$. However, with age, the risk of potentially hazardous prescribing increased with increasing age until 35-44 years old (adjusted OR $2.34,95 \%$ CI 2.26 to 2.42 ) and then began decreasing. Women were found to have higher odds of receiving potentiality hazardous prescribing than men $(18.2 \%$ vs $12.2 \%$ in men, adjusted OR $1.43,95 \%$ CI 1.41 to 1.45$)$. For the practice-level characteristics, it was observed that patients from the most deprived localities had higher odds of receiving potentially hazardous prescribing compared with patients from the least deprived localities (adjusted OR 1.10, 95\% CI 1.03 to 1.17). In comparison with England, patients in
Northern Ireland were at highest risk of receiving potentially hazardous prescribing (adjusted OR 1.47, 95\% CI 1.33 to 1.63), followed by Scotland (adjusted OR 1.17 95\% CI 1.11 to 1.23 ).

Patient and practice characteristics associated with inadequate medication monitoring indicators (composite 2)

Table 3 presents the prevalence and ORs for inadequate medication monitoring indicators (composite 2 , M1-M4). Like the potentially hazardous prescribing composite, women were found to have a higher risk of experiencing inadequate medication monitoring than men (adjusted OR 1.12, 95\% CI 1.05 to 1.20 ) and patients from the more deprived localities (IMD quintiles 3-5) had higher odds of experiencing inadequate medication monitoring than patients from the 
Table 3 Prevalence of patients experiencing at least one inadequate medication monitoring (composite 2) by patient and practice-level characteristics and multilevel logistic regression unadjusted and adjusted ORs (95\% Cls)

\begin{tabular}{|c|c|c|c|}
\hline \multirow[b]{2}{*}{ Variable ( $\mathrm{n}$ at risk) } & \multirow[b]{2}{*}{$\%$ prevalence $(95 \% \mathrm{Cl})$} & \multicolumn{2}{|l|}{ OR $(95 \% \mathrm{Cl})$} \\
\hline & & Unadjusted & Adjusted \\
\hline \multicolumn{4}{|l|}{ Age } \\
\hline$<25(2034)$ & $96.3(95.4$ to 97.1$)$ & 1 & 1 \\
\hline $25-34(4663)$ & 95.9 (95.3 to 96.4$)$ & 0.80 (0.60 to 1.05$)$ & $0.85(0.64$ to 1.12$)$ \\
\hline $35-44(6372)$ & $92.9(92.3$ to 93.5$)$ & 0.45 (0.35 to 0.58$)$ & 0.52 (0.40 to 0.67$)$ \\
\hline $45-54(8558)$ & 90.4 (89.7 to 91$)$ & $0.31(0.25$ to 0.40$)$ & $0.39(0.30$ to 0.50$)$ \\
\hline 55-64 (8274) & 87.6 (86.9 to 88.3 ) & $0.24(0.19$ to 0.30$)$ & $0.31(0.24$ to 0.40$)$ \\
\hline $65-74(6051)$ & 85.5 (84.5 to 86.3$)$ & $0.19(0.15$ to 0.25$)$ & $0.26(0.20$ to 0.34$)$ \\
\hline$>74(6927)$ & 89.1 (88.3 to 89.8$)$ & $0.28(0.22$ to 0.36$)$ & 0.40 (0.31 to 0.51$)$ \\
\hline \multicolumn{4}{|l|}{ Sex } \\
\hline Male (17 280) & 90 (89.6 to 90.5$)$ & 1 & 1 \\
\hline Female (25 599) & 90.3 (89.9 to 90.7$)$ & 1.05 (0.98 to 1.13$)$ & $1.12(1.05$ to 1.20$)$ \\
\hline \multicolumn{4}{|c|}{ Number of drugs on repeat prescription } \\
\hline 0 or $1(4208)$ & 95.6 (94.9 to 96.2$)$ & 1 & 1 \\
\hline $2-4(12283)$ & 92.3 (91.8 to 92.8$)$ & 0.52 (0.44 to 0.62$)$ & 0.57 (0.48 to 0.68$)$ \\
\hline $5-7\left(\begin{array}{llll}10 & 016\end{array}\right)$ & 89.7 (89.1 to 90.3$)$ & $0.37(0.31$ to 0.43$)$ & $0.45(0.38$ to 0.53$)$ \\
\hline $8-10(7216)$ & $88.8(88.1$ to 89.6$)$ & 0.32 (0.27 to 0.38$)$ & $0.42(0.36$ to 0.50$)$ \\
\hline$>10(9156)$ & 86.5 (85.8 to 87.2 ) & $0.26(0.22$ to 0.30$)$ & $0.35(0.29$ to 0.41$)$ \\
\hline \multicolumn{4}{|l|}{ List size } \\
\hline$<6000(6829)$ & 90.1 (89.4 to 90.8$)$ & 1 & 1 \\
\hline $6001-9000$ (14 279) & $91.2(90.8$ to 91.6$)$ & 1.15 (0.84 to 1.56$)$ & $1.12(0.82$ to 1.53$)$ \\
\hline $9001-12000(10448)$ & $88.3(87.7$ to 88.9$)$ & 0.82 (0.58 to 1.17$)$ & $0.83(0.58$ to 1.17$)$ \\
\hline$>12000(11323)$ & $90.7(90.2$ to 91.3$)$ & 0.98 (0.68 to 1.41$)$ & $1.08(0.74$ to 1.58$)$ \\
\hline \multicolumn{4}{|c|}{ Practice-level index of multiple deprivation quintile } \\
\hline 1 least deprived (5653) & 86.9 (86 to 87.7$)$ & 1 & 1 \\
\hline $2(6799)$ & 90 (89.3 to 90.7$)$ & 1.48 (0.98 to 2.24$)$ & 1.57 (1.03 to 2.41$)$ \\
\hline $3(7884)$ & $91.5(90.9$ to 92.1$)$ & 1.88 (1.25 to 2.82$)$ & $1.87(1.23$ to 2.84$)$ \\
\hline $4(9904)$ & 90.9 (90.4 to 91.5$)$ & $1.77(1.20$ to 2.63$)$ & $1.85(1.23$ to 2.76$)$ \\
\hline 5 most deprived (12 639) & 90.3 (89.8 to 90.8$)$ & 1.56 (1.06 to 2.29$)$ & $1.65(1.11$ to 2.46$)$ \\
\hline \multicolumn{4}{|l|}{ Country } \\
\hline England (9790) & $90.2(89.9$ to 90.8$)$ & 1 & 1 \\
\hline Northern Ireland (2552) & $85.9(84.5$ to 87.2$)$ & 0.69 (0.37 to 1.28$)$ & $0.73(0.39$ to 1.38$)$ \\
\hline Scotland (18 489) & $89.7(89.2$ to 90.1$)$ & 1.11 (0.82 to 1.50$)$ & 1.14 (0.84 to 1.55$)$ \\
\hline Wales (12 048) & 91.9 (91.4 to 92.4$)$ & 1.25 (0.90 to 1.73$)$ & $1.28(0.92$ to 1.78$)$ \\
\hline
\end{tabular}

least deprived. However, the opposite was observed with respect to age and polypharmacy. Patients with $>10$ prescriptions had a lower risk of inadequate medication monitoring than patients with $0-1$ repeat prescription (adjusted OR $0.35,95 \%$ CI 0.29 to 0.41 ), and patients aged $>74$ had a lower risk than patients aged $<25$ (adjusted OR $0.40,95 \%$ CI 0.31 to 0.51 ). No significant association was observed for the practice list size or country, and the risk of experiencing inadequate medication monitoring.

\section{DISCUSSION}

\section{Principal findings}

We found that mental health-related potentially hazardous prescribing is common in primary care with considerable variation between general practices for some indicators even after controlling for differences in patient characteristics. The variations were higher for indicators related to benzodiazepine and Z-drug prescribing and monitoring the physical health of patients receiving antipsychotics. In addition, our analyses identified a subset of 11 PSIs with adequate reliability to distinguish between practices thus making them fit for use in benchmarking. ${ }^{47} 50$

This work could also be regarded as a baseline prevalence to evaluate if prescribing safety for people with mental illness is improving in primary care. ${ }^{42}$ However, it is important to consider that the identification of PSIs does not necessarily imply error and sometimes seemingly hazardous prescribing might be the patients' best option. ${ }^{51}$ Still, in general, they are not considered good practice and should be avoided where possible. ${ }^{41}$ Indeed, our findings related to the high rates of inadequate medication monitoring are 
concerning as there is not usually a clinical justification for this. ${ }^{42}$ However, medication monitoring may be affected by patient engagement, quality of data recording or that the monitoring is performed and documented in other settings such as secondary care. Nevertheless, current National Institute for Health and Care Excellence guidelines indicate that primary care should be responsible for antipsychotics (M1) and lithium (M3 and M4) monitoring after the first 12 months of therapy or when the patient's condition has stabilised. ${ }^{52} 53$

\section{Comparison with other studies}

Multiple studies have investigated the safety of prescribing in primary care in the UK or Ireland using PSIs. ${ }^{41-44}$ However, comparing these studies to ours is not ideal due to the different indicators used. The only indicator similarly observed and suitable for comparison is lithium monitoring; Stocks et al observed a prevalence of $19.3 \%$ for inadequate lithium monitoring which is consistent with our subindicator (M3a: monitoring lithium plasma levels within the previous 6 months, 18.61\%). ${ }^{42}$ However, this is lower than our overall lithium monitoring indicator (M3: monitoring lithium plasma levels within the previous 6 months or within the last 3 months if the patient is aged $\geq 65$ years or has a diagnosis of renal impairment or during the first year of treatment, 24.3\%).

Most previous studies examined the overall safety of prescribing in primary care, whereas we aimed to specifically assess mental health-related prescribing. Our approach facilitates the examination of the safety of prescribing more comprehensively for this vulnerable patient population, and to provide a clearer estimate of the magnitude of the safety concerns. For instance, it has been reported that the risk of receiving potentially hazardous prescribing in primary care increases with age. ${ }^{4142} 44$ In contrast, we found that after adjustment, the risk of receiving mental healthrelated potentially hazardous prescribing for patients aged $25-64$ is higher than older patients. Also, although our findings were consistent with previous studies in that polypharmacy was strongly associated with increasing risk of receiving potentially hazardous prescribing, our estimated risk was found to be much higher with the odds of receiving at least one mental health-related potentially hazardous prescription being 30 times higher in people with more than 10 repeat prescriptions in comparison with people with one or no repeat prescription (95\% CI 29.44 to 31.02). Previous research in the general population in primary care reported OR after adjustment ranging from 1.35 to $10 .{ }^{41-44}$

The prevalence of the inadequate medication monitoring composite indicator was influenced predominantly by one indicator (M1). Several audits and studies from multiple countries have reported high prevalence of inadequate metabolic monitoring for people prescribed antipsychotic medication. ${ }^{5455}$ In addition, a systematic review and meta-analysis reported that the proportion of patients receiving the monitoring does not differ between case record studies and database studies. ${ }^{54}$ Therefore, the quality of documentation might not be the main cause for these elevated prevalence values. A systematic review identified several multidimensional barriers to adequate monitoring for patients on antipsychotic medication. ${ }^{56}$

Considering the variation between practices, it has previously been suggested that there are marked variations in mental health prescribing between general practices in the UK. ${ }^{57-60}$ However, the variation in the prevalence of PSIs has only been examined in the UK using general (non-mental health specific) sets of PSIs. ${ }^{4}{ }^{42}$ While the reported ICC $(0.03)$ for the prescribing composite is comparable to previous publications, and is generally interpreted as low, the variation is large in absolute terms (varying from 3.2\% to $24.1 \%$ ) and is adequately reliable to detect true practice differences, ${ }^{42} 475061$ which suggest small but statistically and clinically significant variation between practices. ${ }^{61}$ However, in the USA, substantial variation in prescribing safety between geographical regions based on the 'Coefficient of Variation' was reported using indicators from the Healthcare Effectiveness Data and Information Set. ${ }^{62}$

\section{Strengths and limitations of the study}

To our knowledge, this is the first study to specifically assess the safety of mental health-related prescribing in primary care using a suite of PSIs that were developed with a panel of mental health experts. We examined the safety of prescribing in a large population and evaluated variation in the prevalence of PSIs between general practices across the UK.

This study has several limitations. Due to the nature of medical records, we can only examine coded events in health records, which could differ from the care actually delivered. For example, in a PSI where the absence of a test or prescription is the numerator, the resulting potential bias may be overestimating the prevalence of potentially hazardous care if care was delivered but not documented or if it was delivered outside of primary care. This is particularly relevant for monitoring indicators as some tests could take place in secondary care settings or in other specialist mental health settings. Conversely, when the presence of a test or prescription is the numerator, underestimation is the more likely bias. Hence, this would raise the need for more effective documentation. Furthermore, included practices may not be representative of all the practices in their country, particularly when considering the smaller number of practices which were included from some UK regions. The shift of electronic health record providers in general practices from Vision to EMIS and TPP SystmOne clinical systems has led to reduction of practices contributing to the CPRD GOLD in 
England. ${ }^{63}$ In addition, comparing the findings of this research to international data could be complicated due to potential differences in data recording. ${ }^{42}$ However, the safety concerns raised are likely to be relevant to other countries. ${ }^{35}$

\section{Implications and suggestions for future research}

PSIs represent a valuable and efficient tool to assess and monitor the safety of prescribing in populations with mental illness. Measuring and identifying a safety issue is the first step towards changing practice. ${ }^{65}$ The information obtained by these indicators may enable health providers and policymakers to scrutinise crucial aspects concerning prescribing, identifying improvement targets, supporting development of improvement efforts to help reduce medication-related harm, prioritising efforts for patients with increased risk of triggering the indicators and addressing avoidable health inequalities.

The implemented PSIs could be used to monitor and identify targets for improvement on a national or a local level, as with the Medication Safety Dashboard and the QOF in the UK. ${ }^{3166}$ They could also be used to assess the safety of prescribing before and after the proposed new and integrated model of primary and community mental healthcare in England. ${ }^{67}$ PSIs could also be applied on a patient level to identify individuals at risk of medication-related harm and help towards achieving the WHO Global Patient Safety Challenge of reducing the level of severe, avoidable harm related to medicines, as with the successful pharmacist-led information technology intervention for medication errors (PINCER), the pharmacist-led safety medication dashboard (SMASH) (based on PINCER PSIs) and the Data-Driven Quality Improvement in Primary Care programme. ${ }^{21-25}$ However, further work is still needed to explore the practicality of these indicators in general practices using either existing interventions that demonstrated effectiveness in improving prescribing safety or using new interventions designed specifically to support improvement for patients with mental illness.

The low reliability for some indicators indicates that some practices had inadequate numbers of patients 'at risk' to be used for comparison. However, the composite indicators showed adequate reliability across all or most practices. However, it is important to recognise the disadvantages of composite indicators (eg, could be misleading and lack transparency). ${ }^{68} 69$ For instance, the monitoring composite (composite 3) was dominated by a single indicator. Therefore, for the purpose of benchmarking, composite indicators along with individual reliable indicators could be used, improving our confidence that they correctly define practices as having above average or below average rates of potentially hazardous prescribing and inadequate monitoring. ${ }^{41}$ In addition, there might be a need to regularly review the appropriateness of individual indicators within the composites. ${ }^{68}$ Nevertheless, the reliability estimate provided is only relevant to compare practices at an aggregated level (meso-level) and therefore individual PSIs with low reliability could still be used to identify patients at risk of harm for improvement interventions at a patient level (microlevel) and also to assess the safety nationally or to compare it internationally (macro-level). ${ }^{70}$

Several concerns and opportunities can be drawn from these findings, highlighting the need for further research into interventions to improve prescribing safety for patients with mental illness. Several studies have explored means to improve different aspects of medication safety issues for patients with mental illness, including: specialist mental health clinical pharmacy teams in primary care to improve medicine optimisation, ${ }^{71}$ improved and greater collaboration between GPs and secondary care, ${ }^{72}$ increased knowledge and skills training for managing mental illness in primary care ${ }^{72}$ and better communication between GPs and psychiatrists to help improve metabolic monitoring for patients on antipsychotics. ${ }^{73}$ We envisage that our PSIs may be used to guide these improvement efforts, and could play an important role in developing new services for reviewing mental health medications delivered by the primary care networks. ${ }^{10}$

Future research should also focus on the predictive validity of these indicators. The PSIs in our study may have adequate face and content validity as they were developed using the Delphi consensus approach after reviewing the available evidence supporting each indicator. ${ }^{35}$ However, their predictive validity in terms of patient outcomes remains uncertain. Therefore, future work needs to investigate how well these PSIs can predict harm and hospital admission. In addition, with unexplained variations in the prevalence of PSIs observed between practices, there is a need to elucidate the sources of these variations which may be due to differences in the prevalence of patient comorbidities, differences in data recording or in local treatment policies and guidelines.

\section{CONCLUSION}

This is the first study to specifically assess the safety of mental health-related prescribing in primary care using a tailored suite of PSIs. The findings suggest that potentially hazardous prescribing and inadequate medication monitoring are common in those with mental illness in primary care with high variation between practices for some indicators. The information obtained by the indicators may enable health providers to identify improvement targets and support development of improvement efforts to help reduce medication-related harm for people with mental illness. This study has also identified a subset of indicators and composite indicators with good reliability making them fit for use in benchmarking. 
Author affiliations

${ }^{1}$ Centre for Pharmacoepidemiology and Drug Safety, Division of Pharmacy and Optometry, School of Health Sciences, Faculty of Biology, Medicine and Health, University of Manchester, Manchester, UK

${ }^{2}$ Department of Clinical Pharmacy, College of Pharmacy, Taif University, Taif, Saudi Arabia

${ }^{3}$ Manchester Academic Health Science Centre, Manchester, UK

${ }^{4}$ NIHR Greater Manchester Patient Safety Translational Research Centre, Faculty of Biology, Medicine and Health, University of Manchester, Manchester, UK ${ }^{5}$ Division of Primary Care, School of Medicine, Faculty of Medicine and Health Sciences, University of Nottingham, Nottingham, UK

${ }^{6}$ Pharmacy Department, Greater Manchester Mental Health NHS Foundation Trust, Manchester, UK

\section{Twitter Wael Y Khawagi @Khawagi and Alison K Wright} @_AlisonWright

Contributors The original idea for the research was developed by WYK, RNK and DS, with input from DMA and AA. WYK conducted the analysis with input from RNK, MJC, AKW, DMA and DS. WYK, MJC and AKW had full access to the data. All authors contributed to the interpretation of the findings. WYK drafted the paper and all authors reviewed and edited the manuscript, and approved the version to be published. WYK is the guarantor of the study.

Funding Access to the CPRD was funded by the University of Manchester. DMA, MC and AJA are funded by the National Institute for Health Research (NIHR) Greater Manchester Patient Safety Translational Research Centre (PSTRC-2016-003).

Disclaimer The funder had no involvement in the study design; in the collection, analysis and interpretation of the data; in the writing of the report; and in the decision to submit the paper for publication. The content of this paper is solely the responsibility of the authors and does not reflect the views of the funder.

\section{Competing interests None declared.}

\section{Patient consent for publication Not required.}

Ethics approval This study is based in part on data from the Clinical Practice Research Datalink obtained under licence from the UK Medicines and Healthcare products Regulatory Agency. The data are provided by patients and collected by the NHS as part of their care and support. The interpretation and conclusions contained in this study are those of the authors alone. The study and use of CPRD data were approved by the Independent Scientific Advisory Committee (ISAC) for MHRA database research (ref 19_234A).

Provenance and peer review Not commissioned; externally peer reviewed.

Data availability statement Electronic health records are, by definition, considered "sensitive" data in the UK by the Data Protection Act and cannot be shared via public deposition because of information governance restriction in place to protect patient confidentiality. Access to data is available only once approval has been obtained through the individual constituent entities controlling access to the data. The primary care data can be requested via application to the Clinical Practice Research Datalink (https://www.cprd.com).

Supplemental material This content has been supplied by the author(s). It has not been vetted by BMJ Publishing Group Limited (BMJ) and may not have been peer-reviewed. Any opinions or recommendations discussed are solely those of the author(s) and are not endorsed by BMJ. BMJ disclaims all liability and responsibility arising from any reliance placed on the content. Where the content includes any translated material, BMJ does not warrant the accuracy and reliability of the translations (including but not limited to local regulations, clinical guidelines, terminology, drug names and drug dosages), and is not responsible for any error and/or omissions arising from translation and adaptation or otherwise.
Open access This is an open access article distributed in accordance with the Creative Commons Attribution Non Commercial (CC BY-NC 4.0) license, which permits others to distribute, remix, adapt, build upon this work noncommercially, and license their derivative works on different terms, provided the original work is properly cited, appropriate credit is given, any changes made indicated, and the use is noncommercial. See: http://creativecommons.org/licenses/by-nc/4. $0 /$.

\section{ORCID iDs}

Wael Y Khawagi http://orcid.org/0000-0002-9489-1697

Alison K Wright http://orcid.org/0000-0002-8418-8332

Richard Neil Keers http://orcid.org/0000-0001-7854-8154

\section{REFERENCES}

1 McManus S, Bebbington P, Jenkins R. Mental health and wellbeing in England: adult psychiatric morbidity survey 2014 Leeds: NHS Digital, 2016. Available: https://www.gov. uk/government/uploads/system/uploads/attachment_data/file/ 556596/apms-2014-full-rpt.pdf [Accessed 3 Apr 2018].

2 Ilyas S, Moncrieff J. Trends in prescriptions and costs of drugs for mental disorders in England, 1998-2010. Br J Psychiatry 2012;200:393-8.

3 Olfson M, Marcus SC. National patterns in antidepressant medication treatment. Arch Gen Psychiatry 2009;66:848-56.

4 Verdoux H, Tournier M, Bégaud B. Antipsychotic prescribing trends: a review of pharmaco-epidemiological studies. Acta Psychiatr Scand 2010;121:4-10.

5 Digital NHS. Prescriptions Dispensed in the Community - Statistics for England, 2006-2016: National Statistics publication, 2017. Available: https://digital.nhs.uk/data-andinformation/publications/statistical/prescriptions-dispensedin-the-community/prescriptions-dispensed-in-the-communitystatistics-for-england-2006-2016-pas [Accessed 22 Mar 2020].

6 Mann K, Rothschild JM, Keohane CA, et al. Adverse drug events and medication errors in psychiatry: methodological issues regarding identification and classification. World J Biol Psychiatry 2008;9:24-33.

7 Hodkinson A, Tyler N, Ashcroft DM, et al. Preventable medication harm across health care settings: a systematic review and meta-analysis. BMC Med 2020;18:313.

8 Alshehri GH, Keers RN, Ashcroft DM. Frequency and nature of medication errors and adverse drug events in mental health hospitals: a systematic review. Drug Saf 2017;40:871-86.

9 Maidment ID, Lelliott P, Paton C. Medication errors in mental healthcare: a systematic review. Qual Saf Health Care 2006;15:409-13.

10 Naylor C, Bell A, Baird B. Mental health and primary care networks: Understanding the opportunities: The King's fund, 2020. Available: https://www.kingsfund.org.uk/sites/ default/files/2020-07/Mental\%20Health\%20and\%20PCNs\% 20online\%20version_1.pdf [Accessed 24 Dec 2020].

11 NHS England. Integrating mental health therapy into primary care. Available: https://www.england.nhs.uk/mental-health/ adults/iapt/integrating-mental-health-therapy-into-primarycare/ [Accessed 16 Feb 2021].

12 The Mental Health Taskforce. The five year forward view for mental health, 2016. Available: https://www.england.nhs.uk/ wp-content/uploads/2016/02/Mental-Health-Taskforce-FYFVfinal.pdf [Accessed 24 Dec 2020].

13 Mind. Better equipped, better care: improving mental health training for GPs and practice nurses, 2017. Available: https:// www.mind.org.uk/media-a/4501/find-the-words-report-betterequipped-better-care.pdf [Accessed 2 Jun 2021]. 
14 England L. RCGP position statement on mental health in primary care. Primary Care Mental Health Steering Group, 2017.

15 Baird B, Charles A, Honeyman M. Understanding pressures in general practice. King's Fund London, 2016.

16 Dall T, Reynolds R, Chakrabarti R. The complexities of physician supply and demand: projections from 2018 to 2033. Washington, DC: Association of American Medical Colleges, 2020.

$17 \mathrm{OECD} / \mathrm{EU}$. Strengthening primary care systems. Health at a Glance: Europe 2016 - State of Health in the EU Cycle. Paris: OECD Publishing, 2016.

18 Thomas SK, McDowell SE, Hodson J, et al. Developing consensus on hospital prescribing indicators of potential harms amenable to decision support. Br J Clin Pharmacol 2013;76:797-809.

19 Avery AJ, Dex GM, Mulvaney C, et al. Development of prescribing-safety indicators for GPs using the Rand appropriateness method. Br J Gen Pract 2011;61:e526-36.

20 Acute Care and Workforce, Acute Care and Quality, Care Quality Commission. The report of the short life Working group on reducing medication-related harm: department of health and social care, 2018. Available: https://www.gov.uk/ government/uploads/system/uploads/attachment_data/file/ 683430/short-life-working-group-report-on-medication-errors. pdf [Accessed 2 Apr 2018].

21 WHO. Medication Without Harm - Global Patient Safety Challenge on Medication Safety Geneva, 2017. Available: http://apps.who.int/iris/bitstream/handle/10665/255263/WHOHIS-SDS-2017.6-eng.pdf [Accessed 4 Apr 2018].

22 Avery AJ, Rodgers S, Cantrill JA, et al. A pharmacist-led information technology intervention for medication errors (pincer): a multicentre, cluster randomised, controlled trial and cost-effectiveness analysis. Lancet 2012;379:1310-9.

23 Jeffries M, Gude WT, Keers RN, et al. Understanding the utilisation of a novel interactive electronic medication safety dashboard in general practice: a mixed methods study. BMC Med Inform Decis Mak 2020;20:69.

24 Dreischulte T, Donnan P, Grant A, et al. Safer Prescribing--A Trial of Education, Informatics, and Financial Incentives. N Engl J Med 2016;374:1053-64.

25 Peek N, Gude WT, Keers RN, et al. Evaluation of a pharmacist-led actionable audit and feedback intervention for improving medication safety in UK primary care: an interrupted time series analysis. PLoS Med 2020;17:e1003286.

26 Barnett KN, Bennie M, Treweek S, et al. Effective feedback to improve primary care prescribing safety (EFIPPS) a pragmatic three-arm cluster randomised trial: designing the intervention ( ClinicalTrials.gov registration NCT01602705). Implement Sci 2014;9:133.

27 Guthrie B, Kavanagh K, Robertson C, et al. Data feedback and behavioural change intervention to improve primary care prescribing safety (EFIPPS): multicentre, three arm, cluster randomised controlled trial. BMJ 2016;354:i4079.

28 Dreischulte T, Grant A, Donnan P, et al. A cluster randomised stepped wedge trial to evaluate the effectiveness of a multifaceted information technology-based intervention in reducing high-risk prescribing of non-steroidal antiinflammatory drugs and antiplatelets in primary medical care: the DQIP study protocol. Implement Sci 2012;7:24.

29 Wessell AM, Ornstein SM, Jenkins RG, et al. Medication safety in primary care practice: results from a PPRNet quality improvement intervention. Am J Med Qual 2013;28:16-24.
30 PRIMIS Team. Pincer national Rollout: progress report to NHS England and the AHSN network, 2020. Available: https://www.nottingham.ac.uk/primis/documents/pincer/pincerprogress-report-ext-exec-summary-july-2020.pdf [Accessed 6 May 2021].

31 NHS digital. Quality and outcomes framework. Available: https://qof.digital.nhs.uk [Accessed 12 Oct 2020].

32 All Wales Medicines Strategy Group. National prescribing indicators 2020-2021: supporting safe and optimised prescribing, 2020. Available: https://awmsg.nhs.wales/files/ national-prescribing-indicators/national-prescribing-indicators2020-2021-pdf/ [Accessed 28 Apr 2021].

33 Scotland PH. National therapeutic indicators: Dashboard, 2020. Available: https://beta.isdscotland.org/find-publicationsand-data/health-services/pharmacy-and-prescribing/nationaltherapeutic-indicators-data-visualisation/20-october-2020/ dashboard/ [Accessed 10 May 2021].

34 Khawagi WY, Steinke DT, Nguyen J, et al. Identifying potential prescribing safety indicators related to mental health disorders and medications: a systematic review. PLoS One 2019;14:e0217406.

35 Khawagi WY, Steinke DT, Nguyen J, et al. Development of prescribing safety indicators related to mental health disorders and medications: modified e-Delphi study. Br J Clin Pharmacol 2021;87:189-209.

36 Herrett E, Gallagher AM, Bhaskaran K, et al. Data resource profile: clinical practice research Datalink (CPRD). Int J Epidemiol 2015;44:827-36.

37 Springate DA, Kontopantelis E, Ashcroft DM, et al. ClinicalCodes: an online clinical codes Repository to improve the validity and reproducibility of research using electronic medical records. PLoS One 2014;9:e99825.

38 Lunt M, Pye S, Movahedi M. DrugPrep (STATA): an algorithm to transform RAW CPRD prescriptions data into formatted analysis-ready drug exposure data. (version v2.0.0). Zenodo 2018.

39 Pye SR, Sheppard T, Joseph RM, et al. Assumptions made when preparing drug exposure data for analysis have an impact on results: an unreported step in pharmacoepidemiology studies. Pharmacoepidemiol Drug Saf 2018;27:781-8.

40 Butterworth S. An audit of clozapine recording in primary care patient records. The Pharmaceutical Journal 2021;306.

41 Guthrie B, McCowan C, Davey P, et al. High risk prescribing in primary care patients particularly vulnerable to adverse drug events: cross sectional population database analysis in Scottish general practice. BMJ 2011;342:d3514-12.

42 Stocks SJ, Kontopantelis E, Akbarov A, et al. Examining variations in prescribing safety in UK general practice: cross sectional study using the clinical practice research Datalink. BMJ 2015;351:h5501.

43 Akbarov A, Kontopantelis E, Sperrin M, et al. Primary care medication safety surveillance with integrated primary and secondary care electronic health records: a cross-sectional study. Drug Saf 2015;38:671-82.

44 Byrne CJ, Cahir C, Curran C, et al. High-Risk prescribing in an Irish primary care population: trends and variation. $\mathrm{BrJ}$ Clin Pharmacol 2017;83:2821-30.

45 Merlo J, Chaix B, Ohlsson H, et al. A brief conceptual tutorial of multilevel analysis in social epidemiology: using measures of clustering in multilevel logistic regression to investigate contextual phenomena. J Epidemiol Community Health $2006 ; 60: 290-7$. 
46 Larsen K, Merlo J. Appropriate assessment of neighborhood effects on individual health: integrating random and fixed effects in multilevel logistic regression. Am J Epidemiol 2005;161:81-8.

47 Hofer TP, Hayward RA, Greenfield S, et al. The unreliability of individual physician "report cards" for assessing the costs and quality of care of a chronic disease. JAMA 1999;281:2098-105.

48 Bradley MC, Motterlini N, Padmanabhan S, et al. Potentially inappropriate prescribing among older people in the United Kingdom. BMC Geriatr 2014;14:1-9.

49 England PH. PHE Technical Guide - Funnel Plots, 2018. Available: https://fingertips.phe.org.uk/profile/guidance [Accessed 4 Aug 2021].

50 Roland M, Elliott M, Lyratzopoulos G, et al. Reliability of patient responses in pay for performance schemes: analysis of national general practitioner patient survey data in England. BMJ 2009;339:b3851.

51 Stocks J. Safer prescribing of medicines - is it easier than we think?: Policy@Manchester Blogs, 2016. Available: http://blog. policy.manchester.ac.uk/posts/2016/01/safer-prescribing-ofmedicines-is-it-easier-than-we-think/ [Accessed 6 Nov 2020].

52 National Institute for Health and Clinical Excellence. Psychosis and schizophrenia in adults: prevention and management. Clinical guideline [CG178]. National Institute for Health and Care Excellence (UK), 2014.

53 National Institute for Health and Clinical Excellence. Bipolar disorder: assessment and management, Clinical guideline [CG185]. National Institute for Health and Care Excellence (UK), 2020.

54 Mitchell AJ, Delaffon V, Vancampfort D, et al. Guideline concordant monitoring of metabolic risk in people treated with antipsychotic medication: systematic review and meta-analysis of screening practices. Psychol Med 2012;42:125-47.

55 Barnes TRE, Bhatti SF, Adroer R, et al. Screening for the metabolic side effects of antipsychotic medication: findings of a 6-year quality improvement programme in the UK. BMJ Open 2015;5:e007633.

56 Ali RA, Jalal Z, Paudyal V. Barriers to monitoring and management of cardiovascular and metabolic health of patients prescribed antipsychotic drugs: a systematic review. $B M C$ Psychiatry 2020;20:581.

57 Pharoah PD, Melzer D. Variation in prescribing of hypnotics, anxiolytics and antidepressants between 61 general practices. Br J Gen Pract 1995;45:595-9.

58 Mackenzie IF, Buckingham K, Wankowski JM, et al. Morbidity, deprivation, and antidepressant prescribing in general practice. Br J Gen Pract 1999;49:884-6.

59 Goyder E, Dibben C, Grimsley M, et al. Variation in prescribing for anxiety and depression: a reflection of health inequalities, cultural differences or variations in access to care? Int J Equity Health 2006;5:4.
60 Tsimtsiou Z, Ashworth M, Jones R. Variations in anxiolytic and hypnotic prescribing by GPs: a cross-sectional analysis using data from the UK quality and outcomes framework. Br J Gen Pract 2009;59:e191-8.

61 Guthrie B, Yu N, Murphy D, et al. Measuring prevalence, reliability and variation in high-risk prescribing in general practice using multilevel modelling of observational data in a population database. Health Services and Delivery Research 2015;3:1-140.

62 Zhang Y, Baicker K, Newhouse JP. Geographic variation in the quality of prescribing. N Engl J Med 2010;363:1985-8.

63 Gulliford MC, Sun X, Anjuman T, et al. Comparison of antibiotic prescribing records in two UK primary care electronic health record systems: cohort study using CPRD gold and CPRD aurum databases. BMJ Open 2020;10:e038767.

64 Kontopantelis E, Stevens RJ, Helms PJ, et al. Spatial distribution of clinical computer systems in primary care in England in 2016 and implications for primary care electronic medical record databases: a cross-sectional population study. BMJ Open 2018;8:e20738.

65 Elseviers M, Wettermark B, Almarsdóttir AB. Drug utilization research: methods and applications. John Wiley \& Sons, Ltd, 2016.

66 Department of Health and Social Care. Medicine safety: indicators for safer prescribing, 2018. Available: https://www. gov.uk/government/publications/medicine-safety-indicators-forsafer-prescribing [Accessed 12 Oct 2020].

67 NHS. NHS Long Term Plan 2019 [cited 202029 December]. Available: https://www.longtermplan.nhs.uk [Accessed 16 Feb 2021].

68 Barclay M, Dixon-Woods M, Lyratzopoulos G. The problem with composite indicators. BMJ Qual Saf 2019;28:338-44.

69 Friebel R, Steventon A. Composite measures of healthcare quality: sensible in theory, problematic in practice. BMJ Qual Saf 2019;28:85-8.

70 Barbazza E, Klazinga NS, Kringos DS. Exploring the actionability of healthcare performance indicators for quality of care: a qualitative analysis of the literature, expert opinion and user experience. BMJ Qual Saf 2021:bmjqs-2020-011247.

71 Raynsford J, Dada C, Stansfield D, et al. Impact of a specialist mental health pharmacy team on medicines optimisation in primary care for patients on a severe mental illness register: a pilot study. Eur J Hosp Pharm 2020;27:31-5.

72 Mykletun A, Knudsen AK, Tangen T, et al. General practitioners' opinions on how to improve treatment of mental disorders in primary health care. interviews with one hundred Norwegian general practitioners. BMC Health Serv Res 2010;10:35.

73 Mangurian C, Giwa F, Shumway M, et al. Primary care providers' views on metabolic monitoring of outpatients taking antipsychotic medication. Psychiatr Serv 2013;64:597-9. 